\title{
Diferenciais de rendimento entre os setores de serviços e da indústria no Brasil: uma análise de decomposição *
}

\author{
Luciana Pacheco Trindade Lacerda ** \\ Alexandre Nunes Almeida ${ }^{* * *}$
}

\begin{abstract}
Resumo
Este trabalho teve por objetivo analisar o diferencial de rendimentos entre os setores de serviços e da indústria no Brasil com base nas PNADs para os anos de 2004, 2009 e 2014. No primeiro momento, procurou-se analisar o hiato salarial entre os setores citados através da decomposição proposta por Oaxaca e Blinder, seguindo a análise através do método de regressão RIF (Recentered Influence Function). Os resultados sugerem que na decomposição salarial pela média, o hiato salarial se mantém favorável aos trabalhadores do setor de serviços nos três anos analisados. No entanto, a decomposição por quantis indicou que o diferencial de renda entre os setores se mantém mais favorável para o setor de serviços entre 2004 e 2014 para os $75^{\circ}$ e $90^{\circ}$ quantis da distribuição, mas não nos quantis inferiores, favorecendo mais os trabalhadores da indústria.
\end{abstract}

Palavras-chave: Diferencial de rendimento; Setores de serviços e de indústria; Decomposição de Oaxaca-Blinder; Regressão RIF.

\begin{abstract}
Income gap between service and industry sectors in Brazil: a decomposition analysis

The objective of this study was to analyze the income differential between the service and industry sectors in Brazil based on the PNADs for the years 2004, 2009 and 2014. First, the wage gap was analyzed between the sectors mentioned using the decomposition by Oaxaca and Blinder, followed by an analysis employing the RIF (Recentered Influence Function) regression method. The results suggest that in the average wage decomposition the wage gap remains favorable to service sector workers in the three years analyzed. However, the analysis of quantiles indicated that the income differentials between sectors was more favorable to the services sector between 2004 and 2014 for the 75th and 90th quantiles of the distribution. In the lower quantiles, however, these differentials were more favorable to the workers in the industry sector.
\end{abstract}

Keywords: Income gap; Service and industry sectors; Oaxaca-Blinder decomposition; RIF regression JEL J21, J24, J31.

\section{Introdução e Contexto}

Com a maior parte da população brasileira vivendo em áreas urbanas, não é novidade que o setor de serviços venha demonstrando alta capacidade de agregar novos postos de trabalho quando comparado aos setores industrial e agropecuário. Como observado por Pereira et al. (2012), o fato do setor terciário ser mais intensivo em trabalho contribui como um dos

\footnotetext{
* Artigo recebido em 13 de junho de 2017 e aprovado em 2 de março de 2018.

${ }^{* *}$ Mestra em Economia Aplicada pela Escola Superior de Agricultura "Luiz de Queiroz" da Universidade de São Paulo (Esalq/USP), Piracicaba, SP, Brasil. E-mail: lucianalacerda@id.uff.br.

${ }^{* * *}$ Professor Associado do Departamento de Economia, Administração e Sociologia da Escola Superior de Agricultura "Luiz de Queiroz" da Universidade de São Paulo (Esalq/USP). Piracicaba, SP, Brasil. E-mail: alex.almeida@usp.br.
} 
principais motivos da existência de um processo migratório de mão de obra excedente da indústria e do campo para o supracitado setor (Scatolin et al., 2007).

Enquanto o número de empregos formais na indústria retrai, o setor de serviços tem seguido uma trajetória oposta, com aumentos da sua participação no emprego e no Produto Interno Bruto (PIB) (IBGE, 2014). Em 2014, segundo o IBGE, o setor industrial registrou queda de $1,2 \%$ no acumulado comparado à expansão de $0,7 \%$ no PIB no setor de serviços nesse mesmo ano.

Apesar do setor de serviços ser injustamente rotulado como um setor improdutivo, e pelo fato de ter se expandido a partir da absorção de mão de obra excedente da indústria (Kon, 2004; Valotto, 2011) e, mais recentemente, da agricultura que atravessa um processo de modernização (Barros, 2014), os resultados obtidos por Jacinto e Pontual (2015) foram contrários a isto. Entre 2002 a 2009, os autores mostram que houve uma evolução positiva da produtividade desse setor em contraste com o mesmo indicador da indústria. Segundo Silva et al. (2006), as transformações que estão ocorrendo no setor de serviços são consequência de uma mudança estrutural na produção de bens e serviços destinados ao consumidor final, passando a incluir também produtos ligados ao consumo intermediário. Ademais, Silva (2009) acrescenta que o avanço da produtividade do setor terciário se deu pelo fato do mesmo estar se tornando cada vez mais inovador e intensivo em conhecimento devido à informatização e setores de tecnologia da informação (TI).

Diante do cenário descrito, e pela importância econômica, o setor de serviços parece não receber a atenção devida por parte dos pesquisadores (Jacinto e Pontual, 2015). Nota-se que, a literatura atual é majoritariamente concentrada em estudos relacionados a temas como a produtividade do trabalhador e a geração de emprego e renda da indústria, por ser, segundo alguns, um setor mais homogêneo e de mais fácil mensuração e avaliação do que o setor terciário (Pereira et al., 2012). Por outro lado, já se sabe que a heterogeneidade da mão de obra do terceiro setor é o que garante o dinamismo das economias por absorver um maior contingente de trabalhadores (Silva et al., 2006; Jacinto; Pontual, 2015).

Isto posto, a hipótese central que norteia este estudo é de que existe uma massa de trabalhadores melhor remunerada, e mais qualificada, no setor de serviços vis-à-vis ao do setor industrial, indo contra a tese de que é na indústria onde estariam as profissões com maior valor agregado (Valotto, 2011; Banco Mundial apud Pereira et al., 2012). Ademais, os diferenciais salariais entre os setores também dependem tanto de características produtivas (observáveis) quanto de características não produtivas (não observáveis) (Jesus, 2015). Assim, é possível que trabalhadores com as mesmas características produtivas, mas empregados em diferentes setores, sejam remunerados de forma heterogênea como se caracteriza, por exemplo, o setor de serviços com o recente crescimento de postos de trabalhos relacionados à tecnologia de informação, comunicação, inovação, etc. (Du Caju et al., 2011).

Assim, os objetivos gerais do trabalho consistem em analisar os diferenciais de salários entre os trabalhadores dos setores de serviços e da indústria no Brasil nos anos de 2004, 2009 
e 2014 com base nos dados da PNADs. Para isso, foi utilizada, no primeiro momento, a decomposição de Oaxaca-Blinder para analisar o diferencial médio entre o setor de serviços e indústria, seguido por uma análise mais detalhada utilizando-se da metodologia RIF (Recentered Influence Function) proposta por Firpo et al. (2009). Esta última tem como alvo melhorar a robustez das estimativas, além de fornecer um retrato mais detalhado das características dos indivíduos devido a sua decomposição de rendimentos auferidos por quantil (Vilela et al., 2012). O setor agropecuário não foi analisado pelo presente trabalho pela falta de dados mais confiáveis, e excesso de ocupações de natureza informal como conta-própria, empregados sem carteira, trabalhadores não remunerados, e aqueles na produção para o próprio consumo.

Entre os principais resultados encontrados, revelou-se que houve um aumento expressivo de trabalhadores no setor de serviços entre 2004 e 2014. Constatou-se, também, que na decomposição salarial pela média, o hiato salarial se mantém favorável aos trabalhadores do setor de serviços nos três anos analisados. Ademais, a decomposição por quantis indicou que o diferencial de renda entre os setores se mantém favorável ao setor de serviços somente para os $75^{\circ}$ e $90^{\circ}$ quantis; contudo, diferenças observadas nesses quantis se revelaram decrescentes entre 2004 e 2014. Nos quantis inferiores de renda, abaixo de 50 , o setor da indústria foi o responsável por remunerar melhor os trabalhadores.

Além desta introdução, este artigo está organizado como se segue. A próxima seção apresenta a revisão de literatura de uma forma sucinta destacando os trabalhos mais relacionados ao escopo do trabalho. A Seção 2 apresenta a metodologia, sendo duas subseções, uma para cada estratégia empírica adotada. A descrição dos dados que foram utilizados é feita nessa mesma seção. Os resultados são expostos na Seção 3. A última seção é dedicada às conclusões e recomendações de políticas baseados nos resultados estimados.

\section{Revisão bibliográfica}

\subsection{Os setores da indústria e serviços}

Essa distinção dos setores da economia em primário, secundário e terciário está associada à teoria dos três setores designadas por Allan Fisher, Colin Clark e Simon Kuznets (Kenessey, 1987). Dado que o setor terciário engloba empresas com diversos perfis, desde o comércio, o serviço público, a saúde e as mais diversas atividades financeiras, essa heterogeneidade surge também como uma barreira para análises mais especificas devido à mudança no tempo das atividades supracitadas (Melo et al., 1998; Silva et al., 2006; Bastos et al., 2008; Hoekman; Matoo, 2008; Jacinto; Pontual, 2015).

Não obstante, a indústria brasileira vem perdendo força nas últimas décadas (Bacha; de Bolle, 2013). Segundo o Ipea, apesar de salários reais da indústria terem se elevado, os mesmos não vêm sendo acompanhados por aumentos da produtividade, fazendo com que o custo da mão-de-obra se eleve. Essa retração pode ser vista tanto no total de empregos quanto no número de horas pagas. Já o setor de serviços é o setor que se encontra em melhor situação 
em comparação com os outros setores (Ipea, 2014; Ipea, 2015). Pastore et al. (2013) atribuem a estagnação da indústria a fatores macroeconômicos a partir de 2010, como a dependência das políticas anticíclicas fiscais e monetárias impulsionadas pela crise de 2008. Além disso, Parnes e Hartung (2013) acreditam que a falta de competitividade desse setor ajuda a explicar sua desaceleração entre os anos de 2005 e 2010, dado que houve um aumento do custo unitário em dólares sobre a utilização de insumos que foi muito superior ao de outros países. Os autores chamam atenção para o baixo nível de produção da indústria em maio de 2012. Nesse período, essa variável estava abaixo da observada em maio de 2008, período pré-crise.

Como já mencionado na introdução, durante muito tempo, o setor de serviços foi visto como um setor improdutivo que apenas complementava os demais setores (Valotto, 2011; Banco Mundial apud Pereira et al., 2012). No entanto, com o decorrer dos anos esse setor passou a ser reconhecido por uma crescente participação no PIB total e por produzir insumos para o setor industrial, sendo decisivo para o nível de produtividade da indústria. (Kon, 1999; Silva et al., 2006; Silva, 2009; Jacinto; Pontual, 2015). Essa relação de interdependência entre os dois setores foi observada por Bastos et al. (2008) para a região Sudeste brasileira. O Rio de Janeiro é um exemplo com uma combinação desigual do dinamismo desses setores, que possui um setor de serviços especializado, mas um setor industrial decadente (Bastos et al., 2008).

As transformações que ocorrem entre setores caracterizam-se por uma reestruturação produtiva que, segundo Kon (2004), ocorre devido às constantes crises na economia. Consequentemente, o país acaba ficando defasado tecnologicamente em relação a outros países de economias emergentes similares ao Brasil. Ademais, Kon também afirma que o setor de serviços brasileiro foi o setor com maior capacidade de absorção de trabalhadores pouco qualificados; mas mesmo assim deu continuidade ao desenvolvimento através do fornecimento de conhecimento especializado. Citando caso análogo, Jacinto e Pontual (2015) concluem que a produtividade do setor de serviços brasileiro cresceu mais do que a produtividade do setor da indústria no período de 2002-2009; conclusão similar à observada por Broadberry e Gupta (2010) na Índia. Além disso, ocorreram modernizações e reestruturações em diversos ramos do setor de serviços brasileiro. Este processo foi mais intenso nas atividades que são capital intensivo, isto é: capazes de gerar encadeamentos estratégicos com outros ramos, com destaque do setor financeiro, das telecomunicações, dos transportes, do comércio e serviços prestados às empresas.

É fato que a maior parte das atividades terciárias ainda mantêm características tradicionais, como informalidade e atraso tecnológico (Silva et al., 2006; Silva, 2009). Contudo, mais recentemente surgem atividades também relacionadas com o contexto de inovação, caracterizadas como Serviços Intensivos em Conhecimento (SIC), da tradução de Knowledge-Intensive Business Services (Kibs) ${ }^{3}$ (Freire, 2006). Enquanto as demais atividades

(3) Segundo a definição da OECD (2006), os SIC são difusores de conhecimento que possuem a capacidade de influenciar no desenvolvimento individual de organizações. Serviços como tecnologia da informação e comunicação, pesquisa e desenvolvimento e serviços financeiros são alguns exemplos típicos de SIC. 
do setor de serviços se caracterizam por gerar pouco valor, empregar mão de obra pouco qualificada e por terem menos tecnologia, os SIC são caracterizados por: i) terem participação expressiva no valor adicionado; ii) empregarem pessoas com alta qualificação; iii) fornecerem tecnologias de informação e; iv) possibilitarem desenvolvimento de estratégia de aprendizado via relação com outros setores (Freire, 2006). A partir do Código Nacional de Atividades Econômicas (CNAE-IBGE) para as atividades definidas por Freire (2006), como SIC, observase que essas atividades cresceram mais do que a média do setor de serviços como um todo. Ademais, devido às suas características multiplicadoras, a expansão dos SIC pode ser vista também como um dos responsáveis por uma mudança de rótulo do setor de serviços, agora visto como um setor mais moderno (Kubota, 2006). Antecipando parte dos resultados, os dados da PNAD utilizados por este estudo, revelam um crescimento de $26 \%$ dessas atividades entre 2004 e 2014. Portanto, pode-se identificar um setor de serviços cada vez mais intensivo em conhecimento, sendo o motivo pelo qual o mesmo forneça insumos para inovação, tanto para a indústria quanto para o próprio setor de serviços, se tornando por sua vez um novo motor do crescimento da economia, aumento da competitividade e geração de empregos (Kubota, 2006).

\subsection{Realocação e migração no mercado de trabalho}

No mercado de trabalho brasileiro, pessoas estão sendo empregadas e desempregadas a todo o momento. A forma com que são criados e destruídos empregos em cada setor não ocorre de maneira uniforme devido às especificidades de cada um (Corseuil et al., 2006). A indústria é o setor que possui a maioria dos trabalhadores formal. Já no setor de serviços o peso do emprego informal aumenta consideravelmente, o que faz, dentre outros fatores, com que o impacto na criação e destruição de empregos ocorra de forma diferente entre eles (Amorim et al., 2006).

Esse processo de realocação também está relacionado com a forma com que a empresa se comporta frente aos choques, como mudanças no ambiente competitivo e abertura econômica, por exemplo. Esse comportamento varia de acordo com a tecnologia e abrangência do choque (Corseuil et al., 2006). Com relação às taxas de realocação, Amorim et al. (2006) mostraram que países em desenvolvimento apresentam taxas maiores vis-à-vis aos países desenvolvidos.

Independente do setor analisado, a realocação do emprego formal é bastante alta sendo grande parte dessa dinâmica explicada pelo nascimento ou morte de novas firmas (Amorim et al., 2006). Amorim et al. (2006) observaram que, dentre os setores com as maiores taxas acima da média de criação e destruição de emprego para o Brasil, encontram-se setores de construção e comércio. Enquanto o comércio apresentou crescimento do emprego formal entre 1991 e 2000, o setor de construção civil foi o setor que mais perdeu empregos no período.

Além dos fatores mencionados acima, Cruz e Santos (2011) destacam que o fluxo e a realocação de mão de obra do setor da indústria para outros setores, como o de serviços, ocorre devido o primeiro setor ser intensivo em capital e, pressupõe-se, ser o de maior produtividade. 
A terceirização dos serviços, que também é responsável pela realocação entre setores, acontece pelo fato de grande parte das atividades desenvolvidas na própria indústria serem repassadas para empresas características do setor de serviços. Essa realocação de mão de obra explica parte da diminuição do peso da indústria na economia (Baumol, 1967).

Kaldor (1957) já indicava essa absorção de mão de obra do setor de serviços como causa do processo de desindustrialização. Esse processo foi denominado como a perda de participação da indústria no emprego total (Rowthorn; Ramaswany, 1999). A reestruturação nas cadeias produtivas, onde o crescimento do setor de serviços se dá através da absorção de mão de obra oriunda da indústria, gera também questionamentos mais atuais sobre o processo de desindustrialização no Brasil (Kon 2004; Cruz; Santos, 2011). Como aponta Squeff (2012), o processo de desenvolvimento econômico, o diferencial de produtividade, a nova divisão internacional do trabalho e a mudança de orientação na política econômica, são algumas justificativas para o processo de desindustrialização. Ademais, a especialização de serviços, que leva a indústria a terceirizar atividades que não são diretamente ligadas à produção contribui significativamente para o processo de desindustrialização, dado que parte da queda da relevância desse setor na população ocupada é explicada pelo processo de terceirização (Cruz; Santos, 2011; Squeff, 2012).

Scatolin et al. (2007) e Tregenna (2008) também definem desindustrialização como uma situação em que, além da redução do emprego industrial como proporção do emprego total, o valor adicionado também seria impactado negativamente na proporção do PIB. A teoria da desindustrialização de Rowthorn e Wells (1987) já argumentava que o avanço no processo de industrialização é capaz de aumentar a produtividade do setor manufatureiro o que, consequentemente, acarreta a realocação de mão de obra para o setor de serviços. Essa realocação é oriunda, principalmente, do avanço tecnológico. Ademais, o setor de serviços é caracterizado como um setor trabalho intensivo e, por esse motivo, absorve cada vez mais a população economicamente ativa.

\section{Metodologia e Dados}

Como já mencionado, este trabalho tem como objetivo mensurar os diferenciais de rendimento entre os setores de serviços e de indústria no Brasil a partir dos microdados das PNADs para os anos de 2004, 2009 e 2014. Os anos de análise foram arbitrariamente escolhidos e optou-se pelas seguintes metodologias: 1) decomposição salarial de OaxacaBlinder; e 2) a regressão quantílica incondicional, desenvolvida mais recentemente por Firpo et al. (2009).

Mais especificamente, a decomposição elaborada por Firpo et al. (2009) se baseia na abordagem de Oaxaca-Blinder. Contudo, a técnica possui a vantagem de ser capaz de separar os efeitos composição (relacionado às variáveis explicativas) e estrutura da variável de interesse ao longo da distribuição e não apenas para a média como na decomposição de OaxacaBlinder. A partir de Firpo et al. (2009) também é possível observar o comportamento de cada 
covariável ao longo de toda distribuição. Esse procedimento pode ser dividido em duas etapas: reponderação e RIF regression, a serem detalhadas na seção 2.2.

\subsection{O método de decomposição salarial Oaxaca-Blinder}

A decomposição salarial Oaxaca (1973) e Blinder (1973) requer a estimativa de regressão linear das equações de rendimentos de cada setor. A partir dessas estimativas, para cada grupo é possível decompor o diferencial de rendimentos em dois componentes, o explicado e o não explicado. O componente explicado (efeito das médias ou efeito composição) é composto pela diferença das médias das características (observáveis) relacionadas ao mercado de trabalho dos dois setores, enquanto, o efeito não explicado, também conhecido como efeito estrutura ou efeito de parâmetros, equivale à diferença nos efeitos que as características produtivas têm sobre a remuneração dos trabalhadores dos dois grupos. Essa diferença é dada pela subtração dos coeficientes estimados dos dois grupos, no que tange ao intercepto e declividade da função e capta a diferença de características observáveis.

Dado dois grupos de trabalhadores, um composto por trabalhadores do setor de serviços $(T=1)$ e outro composto por trabalhadores do setor da indústria $(T=0)$, para um trabalhador $i$, o logaritmo do rendimento $\left(Y_{i}\right)$ será definido por:

$$
Y_{i}=Y_{1 i} \cdot T_{i}+Y_{0 i} \cdot\left(1-T_{i}\right)
$$

Em que:

$T_{i}=1$ se o indivíduo está empregado no setor de serviços;

$T_{i}=0$ se o indivíduo está empregado no setor da indústria;

$Y_{1 i}$ é o rendimento do indivíduo $i$ no setor de serviços; e

$Y_{0 i}$ é o rendimento do indivíduo $i$ no setor da indústria.

Assim como o modelo de determinação de rendimentos de Mincer (1974), a decomposição de Oaxaca e Blinder considera que a expectativa condicional do rendimento dado as características dos trabalhadores como linear. Assim:

$$
E\left[Y_{t i} \mid X\right]=X_{i} \beta_{t}+\varepsilon_{t i}
$$

onde:

$X_{i}$ é o vetor de características do trabalhador $i$ que determinam o salário para o setor $T=0,1 ; \beta$ é o vetor de parâmetros; e

$\varepsilon_{i}$ é o termo de erro.

O último termo é o responsável por abranger as características não observáveis dos trabalhadores. É possível, então, estimar equações de rendimentos para cada grupo separadamente. As equações de salários para cada grupo são especificadas para trabalhadores do setor de serviços e no setor da indústria, respectivamente por: 


$$
\begin{gathered}
\bar{Y}_{1}=\hat{\beta}_{1} \bar{X}_{1} \\
\bar{Y}_{0}=\hat{\beta}_{0} \bar{X}_{0} .
\end{gathered}
$$

Após a estimação das equações de salários, para cada grupo, a diferença do resultado

médio entre os dois setores pode ser definida a partir de:

$$
\begin{aligned}
\Delta_{0}^{\mu}=\bar{Y}_{0}-\bar{Y}_{1} & =E[E(Y \mid X, T=0)]-E[E(Y \mid X, T=1)] \\
=E[Y \mid T & =0]-E[Y \mid T=1] \\
& =\Delta_{X}^{\mu}+\Delta_{S}^{\mu} .
\end{aligned}
$$

O primeiro termo é definido como componente explicado e indica a diferença entre o rendimento médio dos grupos em relação às características no mercado de trabalho. Enquanto o segundo termo sinaliza a diferença nos efeitos que as características produtivas exercem sobre o rendimento dos indivíduos dos dois setores. Blinder (1973) sintetiza que o primeiro termo é "atribuído ao rendimento" e o segundo termo é "atribuído aos coeficientes".

De maneira análoga a (3), a decomposição ${ }^{4}$ de Oaxaca-Blinder pode ser obtida partir de:

$$
\bar{Y}_{0}-\bar{Y}_{1}=\left(\bar{X}_{0}-\bar{X}_{1}\right) \hat{\beta}_{0}+\left(\hat{\beta}_{0}-\hat{\beta}_{1}\right) \bar{X}_{1}
$$

onde o primeiro termo do lado direito mensura o diferencial de rendimento que é explicado pelas características observáveis dos trabalhadores nos setores de serviços e de indústria, ou seja, é o efeito explicado. E o segundo termo indica o efeito não explicado, que estima o diferencial no rendimento decorrente dos efeitos que as características têm sobre cada setor. Em estudos sobre raça e gênero, por exemplo, esse termo é denominado como discriminação (JESUS, 2015), pois reflete as diferenças no rendimento entre indivíduos com as mesmas características, diferenciados somente pelo setor.

Uma das limitações desse modelo, além das que serão analisadas a seguir, é que a discriminação só será exata se a equação de regressão incluir todas as variáveis relevantes associadas às capacidades produtivas dos indivíduos. Segundo Farlie (2005), existe uma dificuldade em mensurar essa parcela.

\subsection{Decomposição por quantil - RIF}

Baseado na decomposição de Oaxaca-Blinder, o método de regressão RIF (Recentered Influence Function) de Firpo et al. (2009) possui a vantagem de ser capaz de separar os efeitos composição e estrutura da variável de interesse para qualquer estatística e não apenas para a média, como na decomposição de Oaxaca-Blinder. A partir disso, é possível dizer que o efeito

(4) Na equação (7), o efeito composição é ponderado pelas médias das características dos trabalhadores do setor de serviços e o efeito estrutura é ponderado pelos coeficientes estimados do setor da indústria. A escolha entre a equação (7) e a equação $\bar{Y}_{0}-\bar{Y}_{1}=\left(\bar{X}_{0}-\bar{X}_{1}\right) \hat{\beta}_{1}+\left(\hat{\beta}_{0}-\hat{\beta}_{1}\right) \bar{X}_{1}$ altera o resultado da decomposição. 
estrutura indica como a distribuição condicional, $F(Y \mid X)^{5}$, muda ao longo do tempo. Em síntese, essa metodologia calcula o propensity score, a partir da reponderação proposta por Firpo, Fortin e Liemeux (FFL) (Firpo et al., 2007), após o cálculo das probabilidades de cada grupo obtidas no propensity score são reponderadas e usadas para a estimação da regressão RIF. Essa regressão considera os quantis de renda e substitui a variável dependente pelo valor estimado do RIF. Mais especificamente, essa metodologia pode ser descrita em dois passos, a saber:

$\underline{\mathbf{1}^{\mathbf{0}} \text { passo: }}$ Reponderação do método proposto por Firpo et al. (2009)

Sendo $v$ uma função da distribuição condicional conjunta de $\left(Y_{1}, Y_{0} \mid T\right)$, a diferença dos $v$ 's entre os dois grupos é chamada de diferencial médio salarial e é determinado a partir da distribuição estatística de $v$ :

$$
\begin{gathered}
\Delta_{0}^{v}=v\left(F_{Y_{0} \mid T=0}\right)-v\left(F_{Y_{1} \mid T=1}\right) \\
=v\left(F_{Y_{0} \mid T=0}\right)-v\left(F_{Y_{1} \mid T=0}\right)+v\left(F_{Y_{1} \mid T=0}\right)-v\left(F_{Y_{1} \mid T=1}\right) .
\end{gathered}
$$

É possível que $X$ seja distribuído de maneira desigual entre os grupos. Por esse motivo, o diferencial médio salarial é decomposto em duas partes, como indicado na segunda linha da equação acima, onde:

$$
\begin{aligned}
& \Delta_{S}^{v}=v\left(F_{Y_{0} \mid T=0}\right)-v\left(F_{Y_{1} \mid T=0}\right) \text { indica o efeito da diferença na estrutura do salário; e } \\
& \Delta_{X}^{v}=v\left(F_{Y_{1} \mid T=0}\right)-v\left(F_{Y_{1} \mid T=1}\right) \text { indica o efeito composição }{ }^{6} \text {, que corresponde ao efeito }
\end{aligned}
$$
na mudança na distribuição de $(X, \varepsilon)$, mantendo o efeito estrutura constante.

Os termos $\left(F_{Y_{1} \mid T=1}\right)$ e $\left(F_{Y_{0} \mid T=0}\right)$ podem ser obtidos, no geral, sem maiores problemas. A metodologia FFL consegue obter o contrafactual $v\left(F_{Y_{1} \mid T=0}\right)$, que é composto pela estrutura salarial dos indivíduos empregados no setor da indústria, mas com distribuição observada e não observada de características dos indivíduos empregados no setor de serviços. A contribuição da FFL se encontra então em estimar de forma não paramétrica este contrafactual. Além de permitir a separação do efeito total em efeito estrutura e efeito composição, é possível obter as estimativas para qualquer estatística de interesse, não se limitando à média, como na decomposição Oaxaca-Blinder.

A decomposição do diferencial de rendimentos nos dois componentes apresentados e os parâmetros da distribuição contrafactual são obtidos por reponderação (FIRPO et al., 2007). O fator reponderação é expresso por:

$$
\omega_{1}(T) \equiv \frac{T}{\hat{p}} \quad \omega_{0}(T) \equiv \frac{1-T}{1-\hat{p}} \quad \omega_{C}(T, X) \equiv\left(\frac{\hat{p}(X)}{1-\hat{p}(X)}\right) \cdot\left(\frac{1-T}{\hat{p}}\right)
$$

em que: $\hat{p}=\frac{\sum_{i=1}^{N} T_{i}}{N}$.

(5) É importante ressaltar que essa distribuição pode ser a média, variância e Gini, enquanto a decomposição de OaxacaBlinder considera somente a média, como exposto em Firpo et al. (2007).

(6) Segundo Firpo et al. (2007), o efeito composição indica o efeito das mudanças na distribuição de $(X, \varepsilon) \mid T=1$ para $(X, \varepsilon) \mid T=0$. 
Já $\omega_{1}(T), \omega_{0}(T)$ e $\omega_{C}(T, X)$ indicam o fator de ponderação para o grupo 1 (setor de serviços), grupo 0 (setor da indústria) e do contrafactual. $\mathrm{O}$ estimador da probabilidade verdadeira de um indivíduo $i$ trabalhar no setor de serviços é definido como $\hat{p}(\cdot)$ e a probabilidade condicional de um indivíduo $i$ dado um vetor de características observáveis, em que $X=x$, é $p(x)=\operatorname{Pr}[T=1 \mid X=x]$. Esse procedimento é usualmente conhecido como propensity score matching.

O processo de reponderação dá resultados mais consistentes, pois tornam as estimativas sensíveis às mudanças na distribuição. O próximo passo dessa metodologia consiste na estimativa de cada covariável ao longo da distribuição para os efeitos de estrutura salarial e composição a partir da regressão quantílica incondicional da função influência recentrada (RIF) proposta por Firpo et al. (2009).

\section{$\underline{2^{\mathbf{0}} \text { passo: }}$ RIF regression.}

Esse procedimento calcula os efeitos parciais de mudanças na distribuição de cada covariável, dada a distribuição estatística de interesse em cada quantil a ser analisado.

A função de influência recentrada (RIF) é definida por $R I F(y ; v)=v(F)+I F(y ; v)$. Onde $v(F)$ é uma função geral e $I F(y ; v)$ corresponde à função de influência do rendimento $y$ para a estatística de distribuição de interesse $v(F)$.

Usando a lei das expectativas iteradas, a distribuição estatística pode ser expressa em termos de expectativas condicionais da função de influência recentrada e se apresenta como uma especificação linear equivalente à regressão MQO (MEIRELES, 2014):

$$
v(F)=E[R I F(y ; v) \mid X=x]=X \gamma
$$

Segundo Firpo et al. (2009), $\gamma$ é denominado parâmetro de interesse e pode ser estimado por MQO.

Após a estimação dos parâmetros de interesse, temos os efeitos estrutura e composição considerando a ponderação:

$$
\begin{gathered}
\widehat{\Delta}_{S}^{v}=\left(\sum_{i=1}^{N} \widehat{\omega}_{1}^{*}\left(T_{i}\right) \cdot X_{i}\right) \cdot\left(\hat{\gamma}_{1}^{v}-\hat{\gamma}_{C}^{v}\right) \\
\left.\hat{\Delta}_{X}^{v}=\left(\sum_{i=1}^{N} \widehat{\omega}_{1}^{*}\left(T_{i}\right) \cdot X_{i}\right) \cdot \hat{\gamma}_{C}^{v}-\sum_{i=1}^{N} \widehat{\omega}_{0}^{*}\left(T_{i}\right) \cdot X_{i}\right) \cdot \hat{\gamma}_{0}^{v}
\end{gathered}
$$

Reescrevendo o efeito composição tem-se que:

$$
\widehat{\Delta}_{X}^{v}=\left(\sum_{i=1}^{N}\left(\widehat{\omega}_{1}^{*}\left(T_{i}\right)-\widehat{\omega}_{0}^{*}\left(T_{i}\right)\right) \cdot X_{i}\right) \cdot \hat{\gamma}_{0}^{v}+\hat{R}^{v},
$$

Em que:

$\left.\hat{R}^{v}=\sum_{i=1}^{N} \widehat{\omega}_{1}^{*}\left(T_{i}\right) \cdot X_{i}\right) \cdot\left(\hat{\gamma}_{1}^{v}-\hat{\gamma}_{C}^{v}\right)$ é uma aproximação do erro, que generaliza a decomposição de Oaxaca-Blinder para qualquer distribuição estatística. 
Para a análise no quantil, a função de influência $I F\left(y ; q_{\tau}\right)$ é dada por $q_{\tau}+\frac{\tau-1\left\{y \leq q_{\tau}\right\}}{f_{y(}\left(q_{\tau)}\right.}$.

Onde:

$1\{$.$\} é uma função indicadora;$

$f_{y}($.$) é a densidade da distribuição marginal de y; e$

$q_{\tau}$ é a população $\tau$ no quantil da distribuição incondicional de $\mathrm{y}$.

A análise feita nesse estudo ocorre em torno da mediana. Nesse sentido, a função de influência da mediana será dada por:

$$
I F(y ; m e)=\frac{\left(\frac{1}{2}-\Pi\{y \leq m e\}\right)}{f(m e)}
$$

Sendo o quantil a estatística de interesse, o $R I F(y ; m e)$ será definido por:

$$
R I F(y ; m e)=m e+\frac{\left(\frac{1}{2}-\Pi\{y \leq m e\}\right)}{f(m e)}
$$

Os estimadores para os diferenciais salariais são obtidos então por:

$$
\widehat{m e}_{0}
$$

$$
\hat{\Delta}_{O}^{m e}=\widehat{m e}_{1}-\quad \hat{\Delta}_{S}^{m e}=\widehat{m e}_{1}-\widehat{m e}_{C} \quad \text { e } \quad \hat{\Delta}_{X}^{m e}=\widehat{m e}_{C}-\widehat{m e}_{0}
$$

O segundo estágio consiste em estimar as regressões RIF. Os autores Firpo et al. (2007) ressaltam que primeiramente deve-se estimar as regressões RIF em cada quantil $\widehat{m e}_{\tau}$ e estimar a densidade do quantil amostral nesse ponto $\left(\hat{f}\left(\widehat{m e}_{t}\right)\right)$ através da densidade de Kernel. Por exemplo, para o quantil de $Y_{i} \mid T=1$, o valor estimado será obtido a partir da seguinte equação:

$$
\widehat{R I F}\left(y ; m e_{1}\right)=\widehat{m e}_{1}+\hat{f}_{1}\left(\widehat{m e}_{1}\right)^{-1} \cdot\left(\frac{1}{2}-1\left\{Y \leq \widehat{m e}_{1}\right\}\right)
$$

Em que:

$\hat{f}_{1}($.$) é o estimador consistente para a densidade de Y_{1} \mid T=1, \hat{f}_{1}($.

Após esse procedimento, as regressões RIF são estimadas substituindo a variável dependente $Y$ pelo valor estimado do $\widehat{\operatorname{IIF}}\left(y, m e_{t}\right)$. Dessa forma, os coeficientes de regressão podem ser expressos por:

$$
\begin{gathered}
\hat{\gamma}_{t}^{m e}=\left(\sum_{i=1}^{N} \widehat{\omega}_{t}\left(T_{i}\right) X_{i} X_{i}^{\prime}\right)^{-1} \cdot\left(\sum_{i=1}^{N} \widehat{\omega}_{t}\left(T_{i}\right) X_{i} \widehat{R I F}\left(Y_{i}, m e_{t}\right)\right), \quad t=0,1 \\
\hat{\gamma}_{C}^{m e}=\left(\sum_{i=1}^{N} \widehat{\omega}_{C}\left(T_{i}, X_{i}\right) X_{i} X_{i}^{\prime}\right)^{-1} \cdot\left(\sum_{i=1}^{N} \widehat{\omega}_{C}\left(T_{i}, X_{i}\right) X_{i} \widehat{R I F}\left(Y_{i}, m e_{C}\right)\right)
\end{gathered}
$$


Por fim, os coeficientes das equações (15) e (16) refletem o efeito marginal de uma mudança na distribuição de $X$ sobre a estatística de interesse, definida como me, nos quantis. A decomposição quantílica incondicional em dois efeitos é expressa como se segue:

$$
\begin{gathered}
\hat{\Delta}_{S}^{m e}=E[X, T=1]^{\mathrm{T}} \cdot \hat{\gamma}_{1}^{m e}-\hat{\gamma}_{C}^{m e} \\
\hat{\Delta}_{X}^{m e}=E[X, T=1]^{\mathrm{T}}-E[X, T=0]^{\mathrm{T}} \cdot \hat{\gamma}_{1}^{m e}-\hat{R}^{m e}
\end{gathered}
$$

Onde:

$$
\hat{R}^{m e}=E[X \mid T=1]^{\mathbf{T}} \cdot \hat{\gamma}_{C}^{m e}-\hat{\gamma}_{0}^{m e}
$$

Na equação (15), o termo $\widehat{\Delta}_{S}^{m e}$ indica o efeito estrutura salarial. Esse efeito representa os diferenciais de rendimentos entre setores que ocorrem devido às diferenças de retornos das características no mercado de trabalho. Já $\widehat{\Delta}_{X}^{m e}$ indica o efeito composição, que se refere aos diferenciais de rendimentos entre setores que ocorrem devido às características do indivíduo.

\subsection{Dados e estatísticas descritivas}

A PNAD é uma pesquisa amostral de suma importância para o acompanhamento de diversas condições socioeconômicas dos indivíduos devido a sua abrangência e periodicidade anual. No entanto, pela sua natureza da coleta de dados, i.e., de cortes transversais, não é possível acompanhar o mesmo indivíduo ao longo do tempo, impedindo que análises quanto à heterogeneidade individual não observada como, por exemplo, motivação, habilidades inatas, etc., entre os indivíduos sejam controladas durante as estimativas. Ademais, mesmo se tratando de uma pesquisa anual, a principal variável de interesse do estudo refere-se ao rendimento recebido no mês de referência da pesquisa (sempre no mês de setembro dos anos não censitários). Outro aspecto com relação aos ganhos recebidos é que existem evidências que quanto maior for o rendimento, maior será a subestimação do seu valor. Contudo, esse problema pode ser minimizado ao incluir na análise somente trabalhadores formais (Rocha, 2003).

Portanto, como o objetivo do trabalho é comparar o diferencial de rendimento entre os indivíduos que trabalham no setor de serviços e na indústria, a variável dependente será o logaritmo natural do rendimento mensal por hora trabalhada, obtido a partir da divisão entre o rendimento mensal e horas trabalhadas, extraídos das PNADs.

Somente informações sobre o trabalho principal acerca dos trabalhadores entre 10 e 64 anos foram incluídas na análise econométrica. Além disto, apenas pessoas ocupadas formalmente no setor de serviços ou na indústria foram consideradas; portanto, sem aquelas ocupadas no setor agropecuário como mencionado na introdução. Em segundo lugar, com relação à condição na unidade familiar, foram excluídos das amostras agregados, pensionistas, empregados domésticos e parentes do empregado doméstico para fins de evitar dupla contagem na análise de rendimentos. 
As informações de atividade da CNAE, rendimentos e horas semanais trabalhadas em relação ao trabalho principal mais raça e gênero não definidos ou ignorados foram excluídos da análise. Pessoas que se autodeclararam indígenas, que não declararam raça, e com experiência negativa também foram excluídas da amostra.

Tendo em vista que o setor de serviços possui um alto índice de informalidade quando comparado à indústria, foram considerados na análise somente trabalhadores com algum registro trabalhista, incluindo nessa categoria os empregados com carteira assinada, os empregadores e os trabalhadores por conta própria que contribuem para Previdência Social ${ }^{7}$ (Rocha 2013; Corseuil; Reis, 2015).

A escolha das variáveis independentes levou em consideração a extensa literatura que analisa a influência das mesmas sobre os rendimentos dos indivíduos (Pinheiro; Ramos, 1994; Ometto et al., 1997; Ometto et al., 1999; Araújo; Ribeiro, 2002; Coelho; Corseuil, 2002; Arabsheibani et al., 2003; O’Neill, 2003; Sachsida et al., 2004; Lovell, 2006; Vaz; Hoffmann, 2007; Becker; Kassouf, 2012; Vilela et al., 2012; Jesus, 2015; Reis, 2017).

Deste modo, as informações escolhidas por este estudo foram: setor de atividade do trabalho principal (indústria e serviços) ${ }^{8}$, região, faixas de estudo, filhos, raça, gênero, experiência ${ }^{9}$, experiência ao quadrado e tecnologia do setor ${ }^{10}$. Todas essas informações são disponibilizadas anualmente, exceto em anos de censo demográfico, através da Pesquisa Nacional por Amostra de Domicílios (PNAD-IBGE).

Mais especificamente, a qualificação do trabalhador foi representada pelos anos de estudo e espera-se que essa variável esteja positivamente relacionada com o rendimento, dado que o investimento em educação tende a promover incrementos no rendimento (Mincer, 1974; Ometto et al., 1999; Coelho; Corseuil, 2002). Já a inserção das binárias de filhos, raça, gênero se justifica por existir uma distinção clara nos salários dos trabalhadores com filhos principalmente mulheres -, negros e mulheres (Arabsheibani et al., 2003; Jesus, 2015). A inclusão da variável experiência ocorreu também, sobretudo, em consequência do estudo de Mincer (1974). Variáveis binárias de região também foram incluídas nas estimações com o objetivo de controlar a desigualdade entre as regiões do país.

Por último, a variável "tecnologia" foi incluída com o objetivo de controlar parte da heterogeneidade do setor de serviços e indústria, assumindo que avanços tecnológicos

(7) Ver variáveis v0711 e v9059 nos dicionários das PNADs dos anos analisados.

(8) O setor de atividade do trabalho principal foi criado a partir da Classificação Nacional de Atividades Econômicas (CNAE-IBGE). O setor da indústria é composto pelas atividades com códigos entre 15010 a 41000 e o setor de serviços incluiu os códigos 50010 a 64020, 65000 a 74090 e 90000 a 93092 e 99000 . Vale ressaltar que as atividades relacionadas à agricultura, construção, serviços domésticos, administração pública e atividades mal definidas não foram consideradas no estudo.

(9) Essa variável foi obtida a partir da proxy definida por Mincer (1974), como ilustrado no quadro 1.

(10) Essa variável foi criada a partir da CNAE-IBGE. 
aumentariam a demanda por trabalhadores mais qualificados (Acemoglu; Autor, 2010). A classificação entre alta e baixa tecnologia foi baseada no trabalho do Dias (2013) de acordo com os setores da CNAE atribuído para cada pessoa ocupada na PNAD. A título de ilustração de atividade de alta tecnologia tem-se o código CNAE 210, fabricação de celulose, papel e produtos de papel, o código CNAE 290, fabricação de máquinas e equipamentos, e assim por diante. O código e a descrição de cada atividade encontram-se no apêndice do artigo.

Consequentemente, as amostras finais totalizaram um total de 89.141 observações em 2004, 96.043 em 2009 e 92.489 em 2014. Como mencionado, estes três anos foram arbitrariamente escolhidos possibilitando retratar distintos períodos da economia brasileira. $\mathrm{O}$ Quadro 1 ilustra as definições das variáveis utilizadas nos modelos econométricos propostos pelo estudo.

Quadro 1

Denominação das variáveis utilizadas nos modelos econométricos.

\begin{tabular}{|c|c|}
\hline Variável dependente & \\
\hline Ln salário/hora & $\begin{array}{l}\text { Logaritmo natural do rendimento por hora trabalhada, obtido através } \\
\text { da divisão do rendimento mensal do trabalho principal (v9532) e horas } \\
\text { trabalhadas semanalmente (v9058) }\end{array}$ \\
\hline \multicolumn{2}{|l|}{ Variáveis explicativas } \\
\hline \multirow{4}{*}{ Binárias Região } & Sudeste $=1 ; 0$ caso contrário (c.c.) \\
\hline & Nordeste $=1 ; 0$ c.c. \\
\hline & Centro-Oeste $=1 ; 0$ c.c. \\
\hline & Sul $=1 ; 0$ caso contrário \\
\hline \multirow{4}{*}{ Binárias Faixas de Estudo } & se ensino fundamental = $1 ; 0$ c.c. \\
\hline & se ensino médio $=1 ; 0$ c.c. \\
\hline & se ensino superior $=1 ; 0$ c.c. \\
\hline & Pós Graduação ${ }^{11}=1 ; 0$ c.c. \\
\hline Filhos & Indica o número de filhos do indivíduo \\
\hline Binária Raça & Raça = 1 se o indivíduo é branco; 0 c.c. \\
\hline Binária Gênero & Gênero = 1 se o indivíduo é homem; 0 c.c. \\
\hline Binária Experiência & $=$ idade-educação-6 \\
\hline Binária Experiência ${ }^{2}$ & Experiência ao quadrado \\
\hline Binária Tecnologia & $\begin{array}{l}\text { Tecnologia = } 1 \text { se a CNAE referente ao setor é considerada de alta } \\
\text { tecnologia }{ }^{12} .\end{array}$ \\
\hline
\end{tabular}

Fonte: Elaboração própria a partir dos dados da PNAD-IBGE.

(11) Para identificar os indivíduos que possuem Mestrado ou Doutorado, utilizaram-se as variáveis v4703 e v0607 para anos anteriores a 2007; e v4803 e v6007 para anos mais recentes simultaneamente. Para as demais faixas de estudo somente v4703 ou v4803 foi utilizada. Indivíduos sem instrução foram omitidos do modelo.

(12) Para a construção dessa variável utilizou-se como base a análise feita por Dias (2013). Considerou-se atividades de alta tecnologia as CNAE três dígitos: 210, 220, 230, 240, 250, 290, 300, 310, 320, 330, 340, 350, 640, 650, 660, 670, 700, 720, 730, 740, 800 e 920. A descrição de cada atividade se encontra no apêndice. 
Pela abertura da Tabela 1, que apresenta as médias das variáveis de interesse, é possível observar através da amostra expandida, que o número de ocupados formalmente no setor da indústria teve um crescimento de $4 \%$ entre 2004 e 2014. Em contrapartida, o número de trabalhadores no setor de serviços teve um crescimento de $34 \%$ no mesmo período analisado.

A taxa de crescimento do rendimento mensal médio e a taxa de crescimento do rendimento mensal médio por hora trabalhada foram três pontos percentuais mais altos para a indústria do que para o setor de serviços. No entanto, é importante acentuar que ao desagregar os rendimentos mensais em percentis, existem diferenças expressivas nos valores absolutos dos rendimentos auferidos entre os trabalhadores do setor da indústria e do setor de serviços em alguns pontos da distribuição, mas não em outros. Em resumo, é possível dizer que o setor de serviços remunera melhor nos percentis $10^{\circ}, 75^{\circ}$ e $90^{\circ}$ em relação ao ocupados na indústria. Por exemplo, em 2004, no percentil $10^{\circ}$, a diferença de rendimentos mensal entre os dois setores foi de $\mathrm{R} \$ 8,19$ a favor do setor de serviços, e subiu para $\mathrm{R} \$ 16,00 \mathrm{em} 2014$. A maior diferença é observada no percentil $90^{\circ}$; cerca $\mathrm{R} \$ 22,50$ a favor do setor terciário em 2004 , e $\mathrm{R} \$ 43,72 \mathrm{em}$ 2014. Por outro lado, para os 50\% de trabalhadores mais ricos, o ano de 2004 sinalizou que os trabalhadores do setor da indústria recebiam, mensalmente, cerca de $\mathrm{R} \$ 12,41$ a mais do que os trabalhadores do setor de serviços, enquanto em 2014, essa diferença caiu para $R \$ 6,32$.

Com relação às características que determinam o estoque de capital humano, os indivíduos na indústria possuem, na média, cerca de 1,13 anos a mais de experiência do que os indivíduos do setor de serviços. Em contraponto, os primeiros possuem, em média, 0,68 anos de estudo a menos no ano mais recente. Tanto a experiência quanto a escolaridade tendem, por motivos diferentes, a aumentar a remuneração do trabalhador (Coelho; Corseuil, 2002). Supondo somente esses dois fatores como determinantes do salário, observa-se que anos de estudo é a variável com maior peso na determinação do diferencial. Observa-se também uma leve queda da diferença dos anos de estudo. Em 2004, trabalhadores do setor de serviços tinham cerca de 0,75 anos de estudo a mais do que os trabalhadores empregados no outro setor. No ano mais recente, essa diferença reduziu para 0,69 anos. A idade média dos trabalhadores em cada setor permaneceu bastante próxima em todos os anos analisados, em torno de 35 anos.

A maior proporção de pessoas brancas no setor da indústria tem orbitado entre $50 \%$ e $60 \%$ entre 2004 e 2014. Observa-se também que em ambos os setores a proporção de pessoas que se declaram brancas vem reduzindo-se ao longo dos anos (61\% para $51 \%$ no período citado). O setor da indústria é também responsável por empregar mais homens (aproximadamente 65\% em 2004), e essa proporção também vem se reduzindo no período analisado (53\% em 2014). Essa estimativa vai ao encontro da análise de Autor (2010) para o período de 1979 a 2009 nos Estados Unidos, em que se observou uma diminuição na proporção de homens no mercado de trabalho. 
Tabela 1

Estatísticas descritivas (médias): serviços e indústria - 2004, 2009 e 2014

\begin{tabular}{|c|c|c|c|c|c|c|c|c|}
\hline & \multicolumn{2}{|c|}{2004} & \multicolumn{2}{|c|}{2009} & \multicolumn{2}{|c|}{2014} & \multicolumn{2}{|c|}{$\begin{array}{c}\text { Var. }(\%) \\
2004-2014\end{array}$} \\
\hline & Indústria & Serviços & Indústria & Serviços & Indústria & Serviços & Indústria & Serviços \\
\hline Rendimento Mensal (R\$)* & $1.208,00$ & $1.242,85$ & $1.402,95$ & $1.408,79$ & $1.706,21$ & $1.718,62$ & $41 \%$ & $38 \%$ \\
\hline Rendimento/hora $(\mathrm{R} \$)^{*}$ & 6,59 & 7,14 & 7,74 & 8,18 & 9,6 & 10,24 & $46 \%$ & $43 \%$ \\
\hline \multicolumn{9}{|l|}{ Percentis } \\
\hline \multicolumn{9}{|l|}{ Rendimento Mensal $(\mathrm{R} \$)^{*}$} \\
\hline $10^{\circ}$ & 164,35 & 172,54 & 239,93 & 253,39 & 354,98 & 371,0 & $116 \%$ & $115 \%$ \\
\hline $25^{\circ}$ & 424,64 & 418,66 & 597,28 & 595,28 & 743,55 & 742,92 & $75 \%$ & $77 \%$ \\
\hline $50^{\circ}$ & 629,45 & 617,04 & 790,68 & 784,25 & $1.032,65$ & $1.026,33$ & $64 \%$ & $66 \%$ \\
\hline $75^{\circ}$ & $1.035,69$ & $1.039,41$ & $1.258,25$ & $1.259,46$ & $1.619,71$ & $1.631,58$ & $56 \%$ & $57 \%$ \\
\hline $90^{\circ}$ & $1.905,76$ & $1.928,22$ & $2.179,02$ & $2.208,25$ & $2.607,15$ & $2.650,87$ & $37 \%$ & $37 \%$ \\
\hline Idade (anos) & 34,24 & 34,42 & 35,37 & 34,95 & 36,54 & 36,09 & $7 \%$ & $5 \%$ \\
\hline Experiência (anos) & 20,10 & 19,52 & 20,46 & 19,31 & 21,11 & 19,98 & $5 \%$ & $2 \%$ \\
\hline Escolaridade (anos) & 8,14 & 8,9 & 8,91 & 9,64 & 9,42 & 10,11 & $16 \%$ & $14 \%$ \\
\hline Homem (\%) & 0,65 & 0,57 & 0,64 & 0,55 & 0,64 & 0,53 & $-2 \%$ & $-7 \%$ \\
\hline Branco $(\%)$ & 0,61 & 0,59 & 0,56 & 0,55 & 0,52 & 0,51 & $-15 \%$ & $-14 \%$ \\
\hline Tecnologia $(\%)$ & 0,29 & 0,27 & 0,28 & 0,29 & 0,30 & 0,29 & $3 \%$ & $7 \%$ \\
\hline Observações (em milhar) & 21,53 & 67,611 & 22,1 & 73,94 & 18,21 & 74,279 & $-15 \%$ & $10 \%$ \\
\hline $\begin{array}{l}\text { Amostra expandida (em } \\
1000)\end{array}$ & 10.540 & 30.621 & 11.540 & 35.262 & 10.941 & 41.037 & $4 \%$ & $34 \%$ \\
\hline
\end{tabular}

Fonte: Elaboração própria a partir dos dados da PNAD- IBGE para os respectivos anos.

Nota: *Valores deflacionados (Base: Set/2014) a partir do Índice Nacional de Preços ao Consumidor (INPC-IPEA).

\section{Resultados}

\subsection{Teste de médias}

Para reforçar a hipótese de que os salários entre os trabalhadores do setor de serviços e da indústria se diferenciam, a média do logaritmo da renda do trabalho principal por horas trabalhadas foi estatisticamente analisada. Essa análise consistiu em realizar um teste para observar se a diferença entre as médias salariais é estatisticamente significativa entre os grupos. O resultado do teste bicaudal rejeitou a hipótese de igualdade entre as médias a um nível de 95\% para os três anos analisados como mostra a Tabela 2.

Tabela 2

Teste de média do logaritmo do salário/hora 2004, 2009 e 2014 (em $\mathrm{R} \${ }^{ \pm}$)

\begin{tabular}{|c|c|c|c|c|c|c|}
\hline \multirow{4}{*}{2004} & Ln salário/hora & Média & Desvio Padrão (DP) & \multicolumn{2}{|c|}{ Intervalo de confiança } & Estatística t \\
\hline & Indústria & 1,478 & 0,808 & 1,467 & 1,489 & $-6,11$ \\
\hline & Serviço & 1,519 & 0,878 & 1,513 & 1,526 & \\
\hline & Diferença média & $-0,041$ & & & & \\
\hline \multirow{4}{*}{2009} & Ln salário/hora & Média & Desvio Padrão (DP) & \multicolumn{2}{|c|}{ Intervalo de confiança } & Estatística t \\
\hline & Indústria & 1,707 & 0,744 & 1,697 & 1,717 & $-5,98$ \\
\hline & Serviço & 1,743 & 0,787 & 1,737 & 1,748 & \\
\hline & Diferença média & $-0,036$ & & & & \\
\hline \multirow{4}{*}{2014} & Ln salário/hora & Média & Desvio Padrão (DP) & \multicolumn{2}{|c|}{ Intervalo de confiança } & Estatística t \\
\hline & Indústria & 1,942 & 0,710 & 1,932 & 1,953 & $-5,09$ \\
\hline & Serviço & 1,973 & 0,750 & 1,968 & 1,979 & \\
\hline & Diferença média & $-0,031$ & & & & \\
\hline
\end{tabular}

Fonte: Elaboração própria a partir dos dados da PNAD-IBGE para os respectivos anos.

Nota: ${ }^{ \pm}$Valores reais de 2014 obtidos a partir do Índice Nacional de Preços ao Consumidor (INPC-Ipea). 


\subsection{Diferenciais de rendimentos na média da distribuição}

A Tabela 3 mostra as predições médias dos salários e o diferencial a cada ano baseado na decomposição de Oaxaca-Blinder. É importante relembrar que para o hiato, os sinais positivo e negativo sinalizam vantagens do setor da indústria e do setor de serviços, respectivamente.

Em 2004, a média dos salários por hora dos trabalhadores da indústria foi $\mathrm{R} \$ 4,65$ e do setor de serviços $\mathrm{R} \$ 4,76$ (em valores de 2014), indicando um diferencial a favor do último setor de R\$ 0,11 por hora trabalhada. Fazendo a mesma comparação para os outros anos, é possível dizer que o diferencial médio teve um aumento equivalente a $\mathrm{R} \$ 0,11 \mathrm{em} 2009$ e $\mathrm{R} \$ 0,15$ em 2014, ambos a favor do setor de serviços.

Os resultados da decomposição também indicaram que os coeficientes do efeito composição apresentaram sinais negativos para todos os anos analisados, contribuindo para que ocorresse um aumento do hiato salarial entre setores. Portanto, supondo que os trabalhadores da indústria tivessem as mesmas características médias relacionadas ao mercado de trabalho dos trabalhadores do setor de serviços, o hiato do rendimento tenderia a ser menor. Caso isso acontecesse, a diferença do rendimento por hora trabalhada diminuiria em $\mathrm{R} \$ 0,15$ em 2004, R\$ 0,13 em 2009, e R\$ 0,04 em 2014.

Seguindo Oaxaca (1973) e Blinder (1973), o efeito estrutura é a parcela do efeito total que reflete as diferenças no rendimento das características dos indivíduos não controladas pelo modelo. Pode-se observar na Tabela 3, que essa parcela contribuiu para o aumento do diferencial entre os setores em 2014. Nesse ano o efeito estrutura foi responsável por $75,2 \%$ do hiato total de rendimentos. Para os demais anos, essa parcela foi responsável por amenizar o hiato entre os setores como mostra os valores negativos de $2004(-36,2 \%)$ e $2009(-20,3 \%)$.

Em resumo, todos os anos analisados mostraram a existência de um diferencial médio em favor do setor de serviços vis-à-vis o setor da indústria. Em 2004, o hiato salarial foi de $2,37 \%$ a favor do setor de serviços, e reduziu-se para $1,72 \%$ em 2009 , e cresceu novamente para $1,94 \%$ em 2014.

Tabela 3

Decomposição de Oaxaca-Blinder: diferencial de rendimentos por setor - 2004, 2009 e $2014(\mathrm{em} \mathrm{R} \$)^{1}$

\begin{tabular}{|c|c|c|c|}
\hline & 2004 & 2009 & 2014 \\
\hline \multicolumn{4}{|l|}{ Diferencial } \\
\hline Rendimento/hora setor da indústria ${ }^{2}$ (I) & $4,65^{* * * *}$ & $5,80^{* * * *}$ & 7,23 *** \\
\hline Rendimento/hora setor de serviços ${ }^{2}$ (II) & $4,76^{* * * *}$ & $5,90 * * *$ & 7,37 *** \\
\hline Var. (\%) ((II/I)-1) & $-2,37 \%$ & $-1,72 \%$ & $-1,94 \%$ \\
\hline \multirow{2}{*}{ Hiato estimado } & $-0,11 * * *$ & $-0,11 * * *$ & $-0,15 * * *$ \\
\hline & $100 \%$ & $100 \%$ & $100 \%$ \\
\hline \multicolumn{4}{|l|}{ Decomposição $^{3}$} \\
\hline \multirow{3}{*}{ Efeito Composição } & 2004 & 2009 & 2014 \\
\hline & $-0,15 * * *$ & $-0,13 * * *$ & $-0,04 * * *$ \\
\hline & $136,18 \%$ & $120,32 \%$ & $24,82 \%$ \\
\hline \multirow{2}{*}{ Efeito Estrutura } & $0,04 * * *$ & $0,02 * * *$ & $-0,11 * * *$ \\
\hline & $-36,18 \%$ & $-20,32 \%$ & $75,18 \%$ \\
\hline
\end{tabular}

Fonte: Elaboração própria a partir da PNAD - IBGE para os respectivos anos.

Notas: *** Estatisticamente significativo a $1 \%$.

${ }^{1}$ Sinal positivo: vantagem do setor da indústria. Sinal negativo: vantagem do setor de serviços.

${ }^{2}$ Valores reais de 2014 obtidos a partir do Índice Nacional de Preços ao Consumidor (INPC-Ipea).

${ }^{3}$ A proporção de cada efeito no hiato total é obtida a partir da divisão do coeficiente de um determinado efeito (composição ou estrutura) e do hiato total estimado. 
Como já mencionado, a decomposição Oaxaca-Blinder trata desse diferencial apenas para a média. Assim, apesar de indicar uma tendência crescente, os resultados obtidos através da metodologia da regressão de RIF, apresentados na próxima seção, podem evidenciar uma tendência do diferencial de rendimentos por quantil, o que torna os resultados mais precisos entre as diferentes camadas da renda auferida pelos trabalhadores.

\subsection{Regressão RIF dos quantis incondicionais entre setores}

A decomposição RIF fornece estimativas do hiato de rendimentos entre setores nos quantis e analisa também a proporção responsável por cada efeito. A Tabela 4 mostra a decomposição dos diferenciais de rendimentos nos quantis para os anos pesquisados, 2004, 2009 e 2014. Todas as estimativas se mostraram estatisticamente diferentes de zero ao nível de significância de $1 \%$.

Entre os resultados mais importantes, pode-se observar que nos três anos analisados o hiato de rendimentos se revelou favorável ao setor de serviços nos dois quantis de renda mais altos, enquanto a indústria remunerou melhor nos três quantis inferiores (2004 foi uma exceção).

Mais especificamente, em 2004, o sinal negativo do efeito composição no $50^{\circ}, 75^{\circ} \mathrm{e}$ $90^{\circ}$ quantis indicou que os trabalhadores do setor de serviços possuem características mais produtivas relacionadas ao mercado de trabalho vis-à-vis os trabalhadores do setor da indústria, como por exemplo, experiência e educação. Decompondo o hiato, observou-se com relação ao efeito composição (explicado) que a diferença do rendimento/hora diminuiria em $\mathrm{R} \$ 0,54$ no $75^{\circ}$ quantil e R\$1,83 no $90^{\circ}$ quantil se os trabalhadores de ambos os setores tivessem as mesmas características ligadas ao mercado de trabalho, o que equivale a 59,41\% e $62,82 \%$, respectivamente, do diferencial. Similarmente, observou-se que o efeito estrutura (não explicado) possui sinais negativos nos dois maiores quantis $\left(-0,37\right.$ reais no $75^{\circ}$ quantil e $-1,09$ reais no $90^{\circ}$ quantil), sinalizando que os retornos das características dos trabalhadores do setor da indústria foram menores que os retornos auferidos pelo outro setor.

Em relação aos quantis inferiores $\left(10^{\circ}\right.$ e $\left.25^{\circ}\right)$, os resultados mostraram que foi a indústria que remunerou melhor os trabalhadores em 2004. Ademais, a decomposição do hiato indicou que no efeito composição a diferença de rendimento/hora entre os dois setores foi praticamente igual (valor de $\mathrm{R} \$ 0,04$ ) no $10^{\circ}$ e no $25^{\circ}$ quantis. Quanto ao efeito estrutura, entre os três quantis supracitados, a diferença de rendimento/hora orbitou entre $\mathrm{R} \$ 0,07$ e $\mathrm{R} \$ 0,15$.

A partir das estimativas apresentadas na Tabela 4, é possível também calcular o diferencial entre os dois setores através da divisão do rendimento por hora trabalhada na indústria e do rendimento por hora trabalhada no setor de serviços (na tabela lê-se: Var. (\%) $((\mathrm{II} / \mathrm{I})-1))$. Em resumo, notou-se que os indivíduos que se encontram no $25^{\circ}$ quantil da distribuição e empregados na indústria receberam, em média, 5,3\% a mais por hora trabalhada do que aqueles empregados no setor de serviços nesse mesmo quantil. A partir do $50^{\circ}$ quantil os trabalhadores do setor de serviços passam a ser mais bem remunerados do que os 
trabalhadores da indústria. Contudo, nesse mesmo quantil, o diferencial obtido foi de apenas $0,46 \%$ a favor dos serviços. Por fim, o $90^{\circ}$ quantil foi responsável por possuir o maior diferencial entre os setores (nesse quantil trabalhadores do setor de serviços auferem, em média, rendimentos $21,6 \%$ maiores).

Seguindo a análise, agora para 2009, os resultados não se mostraram substancialmente diferentes de 2004, isto é, os indivíduos que se encontram nos dois quantis mais baixos eram mais bem remunerados na indústria. $\mathrm{O}$ efeito estrutura se revelou como o principal efeito para o quantil mais baixo $\left(10^{\circ}\right)$ e para o $50^{\circ}$ quantil. No entanto, devido à proporção do efeito composição sobre o hiato total no $50^{\circ}$ quantil, o sinal negativo desse efeito contribuiu para a diminuição do hiato. Vale dizer também que, no $25^{\circ}$ quantil, apesar da pequena proporção do efeito estrutura (de $\mathrm{R} \$ 0,003$ ) sobre o diferencial total, ainda assim o sinal negativo do efeito estrutura contribuiu minimamente para diminuição do hiato entre os setores.

Os quantis que o setor de serviços remunerou melhor, assim como em 2004, são os quantis responsáveis pelos maiores diferenciais. No $75^{\circ}$ quantil, supondo trabalhadores com características idênticas, o hiato reduziria em aproximadamente $\mathrm{R} \$ 0,56$ por hora trabalhada. Essa diminuição é equivalente a $81,5 \%$ do hiato total estimado.

A análise por quantis de renda, em 2009, também revelou que: i) existe um diferencial de $9,2 \%$ por hora trabalhada a favor dos indivíduos empregados na indústria localizados no $10^{\circ}$ quantil; ii) a partir do quantil equivalente à mediana, o setor de serviços remunerou mais $(1,3 \%$ a mais por hora trabalhada); iii) o hiato salarial no $75^{\circ}$ quantil foi de $7,8 \%$ a favor do setor de serviços; e iv) assim como em 2004, o maior diferencial foi encontrado nesse quantil $(8,8 \%$ por hora trabalhada).

Por fim, em 2014, os hiatos obtidos nos $75^{\circ}$ e $90^{\circ}$ quantis indicaram que o setor de serviços remunerou melhor nesses quantis de renda, resultados similares a 2004 e 2009 . O diferencial para o $10 \%$ dos trabalhadores mais ricos equivale a $\mathrm{R} \$ 3,20$ por hora trabalhada, em que R\$ 1,45 é oriundo do efeito composição. Nesse quantil, ambos efeitos contribuíram para a elevação do hiato entre os setores de indústria e de serviços e, a partir do efeito estrutura, tem-se que os trabalhadores da indústria deveriam ter retornos $54,5 \%$ maiores, supondo que os trabalhadores possuem os mesmos retornos médios, mas diferentes características.

Com relação a decomposição RIF para 2014 pode-se dizer que no quantil mais baixo, trabalhadores da indústria auferiram rendimentos $5,7 \%$ maiores. Já o hiato observado no $25^{\circ}$ quantil foi equivalente a $6,7 \%$ por hora trabalhada a favor da indústria. No $90^{\circ}$ quantil, trabalhadores do setor de serviços receberam $18,2 \%$ a mais por hora trabalhada comparado ao setor da indústria.

Nos três anos estudados, o $90^{\circ}$ quantil foi responsável por apresentar maior discrepância salarial entre os setores. Além disso, essa discrepância ocorreu somente a favor do setor de serviços. Essa é uma estimativa esperada considerando a maior proporção de trabalhadores ocupados no setor de serviços e a maior escolaridade dos mesmos ${ }^{13}$.

(13) A Tabela 1 mostra o número de observações e escolaridade média em cada setor. 
Conjuntamente, essas razões possibilitam que mais indivíduos sejam mais bem remunerados no setor de serviços resultando, assim, que o maior hiato de rendimentos seja observado no maior quantil.

Tabela 4

Decomposição da distribuição dos diferenciais de rendimentos nos quantis - 2004, 2009 e $2014\left(\mathrm{em} R \mathbf{R}^{*}\right)^{1}$

\begin{tabular}{|c|c|c|c|c|c|}
\hline & \multicolumn{5}{|c|}{ Quantis } \\
\hline & $10^{\circ}$ & $25^{\circ}$ & $50^{\circ}$ & $75^{\circ}$ & $90^{\circ}$ \\
\hline \multicolumn{6}{|c|}{2004} \\
\hline \multicolumn{6}{|l|}{ Diferencial } \\
\hline Rendimento/hora setor da indústria ${ }^{2}$ (I) & $2,07 * * *$ & $2,84 * * *$ & $4,35 * * *$ & $7,31 * * *$ & $13,53 * * *$ \\
\hline Rendimento/hora setor de serviços ${ }^{2}$ (II) & $1,88 * * *$ & $2,69 * * *$ & $4,37 * * *$ & $8,23 * * *$ & $16,46^{* * * *}$ \\
\hline Var. $(\%)((\mathrm{II} / \mathrm{I})-1)$ & $-9,18 \%$ & $-5,28 \%$ & $0,46 \%$ & $12,59 \%$ & $21,66 \%$ \\
\hline \multirow{2}{*}{ Hiato do rendimento } & $0,20 * * *$ & $0,14 * * *$ & $-0,02 * * *$ & $-0,92 * * *$ & $-2,92 * * *$ \\
\hline & $100 \%$ & $100 \%$ & $100 \%$ & $100 \%$ & $100 \%$ \\
\hline \multicolumn{6}{|l|}{ Decomposição $^{3}$} \\
\hline \multirow{2}{*}{ Efeito composição } & $0,04 * * *$ & $0,04 * * *$ & $-0,09 * * *$ & $-0,54 * * *$ & $-1,83 * * *$ \\
\hline & $22,19 \%$ & $24,45 \%$ & $499,38 \%$ & $59,41 \%$ & $62,82 \%$ \\
\hline \multirow{2}{*}{ Efeito Estrutura } & $0,15 * * *$ & $0,11 * * *$ & $0,07 * * *$ & $-0,37 * * *$ & $-1,09 * * *$ \\
\hline & $77,81 \%$ & $75,55 \%$ & $-399,38 \%$ & $40,59 \%$ & $37,18 \%$ \\
\hline \multicolumn{6}{|c|}{2009} \\
\hline \multicolumn{6}{|l|}{ Diferencial } \\
\hline Rendimento/hora setor da indústria ${ }^{2}(\mathrm{I})$ & $2,94 * * *$ & $3,73 * * *$ & $5,45 * * *$ & $8,77 * * *$ & $15,77 * * *$ \\
\hline Rendimento/hora setor de serviços ${ }^{2}$ (II) & $2,67 * * *$ & $3,69 * * *$ & $5,38 * * *$ & $9,45 * * *$ & $17,15^{* * * *}$ \\
\hline $\operatorname{Var} .(\%)((\mathrm{II} / \mathrm{I})-1)$ & $-9,18 \%$ & $-1,07 \%$ & $-1,28 \%$ & $7,75 \%$ & $8,75 \%$ \\
\hline \multirow[t]{2}{*}{ Hiato do rendimento } & $0,27 * * *$ & $0,04 * * *$ & $0,07 * * *$ & $-0,68 * * *$ & $-1,38 * * *$ \\
\hline & $100 \%$ & $100 \%$ & $100 \%$ & $100 \%$ & $100 \%$ \\
\hline \multicolumn{6}{|l|}{ Decomposição $^{3}$} \\
\hline \multirow{2}{*}{ Efeito composição } & $0,07 * * *$ & $0,04 * * *$ & $-0,06^{* * * *}$ & $-0,55 * * *$ & $-1,68 * * *$ \\
\hline & $26,77 \%$ & $107,14 \%$ & $-93,99 \%$ & $81,49 \%$ & $121,83 \%$ \\
\hline \multirow{2}{*}{ Efeito Estrutura } & $0,19 * * *$ & $-0,003 * * *$ & $0,13 * * *$ & $-0,12 * * *$ & $0,30 * * *$ \\
\hline & $73,23 \%$ & $-7,14 \%$ & $193,99 \%$ & $18,51 \%$ & $-21,83 \%$ \\
\hline \multicolumn{6}{|c|}{2014} \\
\hline \multicolumn{6}{|l|}{ Diferencial } \\
\hline Rendimento/hora setor da indústria ${ }^{2}$ (I) & $3,84 * * *$ & $4,80 * * *$ & $6,49 * * *$ & $10,53 * * *$ & 17,57 \\
\hline Rendimento/hora setor de serviços ${ }^{2}$ (II) & $3,62 * * *$ & $4,48 * * *$ & $6,47 * * *$ & $11,15^{* * *}$ & 20,77 \\
\hline $\operatorname{Var} .(\%)((\mathrm{II} / \mathrm{I})-1)$ & $-5,73 \%$ & $-6,67 \%$ & $-0,31 \%$ & $5,89 \%$ & $18,21 \%$ \\
\hline \multirow{3}{*}{ Hiato do rendimento } & $0,21 * * *$ & $0,32 * * *$ & $0,024 * * *$ & $-0,61$ & $-3,19$ \\
\hline & $100 \%$ & $100 \%$ & $100 \%$ & $100 \%$ & $100 \%$ \\
\hline & $10^{\circ}$ & $25^{\circ}$ & $50^{\circ}$ & $75^{\circ}$ & $90^{\circ}$ \\
\hline \multicolumn{6}{|l|}{ Decomposição $^{3}$} \\
\hline \multirow{2}{*}{ Explicado } & $0,08 * * *$ & $0,10 * * *$ & $0,04 * * *$ & $-0,37 * * *$ & $-1,45 * * *$ \\
\hline & $35,01 \%$ & $32,71 \%$ & $155,43 \%$ & $60,07 \%$ & $45,47 \%$ \\
\hline \multirow{2}{*}{ Não explicado } & $0,14 * * *$ & $0,22 * * *$ & $-0,01 * * *$ & $-0,25 * * *$ & $-1,74 * * *$ \\
\hline & $64,99 \%$ & $67,29 \%$ & $-55,42 \%$ & $39,93 \%$ & $54,53 \%$ \\
\hline
\end{tabular}

Fonte: Elaboração própria a partir da PNAD - IBGE para os respectivos anos.

Notas: $* * *$ Estatisticamente significativo a $1 \%$.

${ }^{1}$ Sinal positivo: vantagem do setor da indústria. Sinal negativo: vantagem do setor de serviços.

${ }^{2}$ Valores reais de 2014 obtidos a partir do Índice Nacional de Preços ao Consumidor (INPC-IPEA).

${ }^{3}$ A proporção de cada efeito no hiato total é obtida a partir da divisão do coeficiente de um determinado efeito (composição ou estrutura) e do hiato total estimado. 


\section{Considerações finais}

O presente artigo se propôs a analisar o diferencial entre o setor de serviços e o setor da indústria no Brasil para os anos de 2004, 2009 e 2014, assim como a contribuição que cada característica tem sobre esse diferencial. Para isso, utilizou-se a decomposição salarial de Oaxaca-Blinder e a regressão quantílica incondicional (RIF regression) proposta por Firpo et al. (2007). A análise preliminar a partir das estatísticas descritivas apontou que o setor da indústria remunerou mais para os quantis $25^{\circ}$ e $50^{\circ}$ enquanto o setor de serviços remunerou mais para os $10^{\circ}, 75^{\circ}$ e $90^{\circ}$ quantis.

A escolha dos setores ocorreu, em primeiro lugar, devido à escassez de estudos envolvendo o setor de serviços e, em segundo lugar, pelo fato desses setores serem responsáveis por quase toda população empregada formalmente no país. Em 2014, por exemplo, esses dois setores somados foram responsáveis por empregar 95\% dos trabalhadores formais (IBGE, 2014). Ademais, um país que deseja maiores níveis de desenvolvimento, melhores condições de vida e competitividade não pode alcançá-lo sem um setor de serviços dinâmico e bem estruturado (Kubota, 2006).

Uma variável indicativa de tecnologia também foi incluída no modelo com o objetivo de controlar um pouco a heterogeneidade do setor de serviços. Além desses fatores, o setor de serviços vem apresentando uma trajetória diferente da exposta diante da retração do setor da indústria observada nas últimas décadas. Devido a essa trajetória decadente da indústria (Bonelli et al., 2013; Parnes; Hartung, 2013; Pastore et al., 2013), supõe-se que ocorreu uma realocação dos trabalhadores do setor industrial para o setor de serviços (Gottschalk; Alves, 2006; Cruz; Santos, 2011). Nesse sentido, considerando a heterogeneidade do setor de serviços e o formato da pesquisa amostral utilizada, o processo de terceirização pode ter contribuído para que o diferencial salarial entre os setores estudados tenha se intensificado, dado que, por exemplo, o indivíduo ocupado no setor administrativo da indústria automobilística (antes considerado ocupado na indústria), passa a ter consciência de que a sua ocupação é diretamente relacionada ao setor de serviços. Infelizmente, essa é uma limitação do presente trabalho não controlada pelos modelos econométricos adotados, e deixada para estudos futuros que procurem abordar também as novas mudanças da lei da trabalhista implementadas em 2017.

A primeira metodologia, proposta por Oaxaca-Blinder, foi capaz de decompor o diferencial em duas parcelas, em que uma é atribuída à diferença das médias das características e outra atribuída à diferença dos parâmetros do modelo. Já a segunda metodologia, além de decompor o diferencial em duas parcelas semelhantes à decomposição de Oaxaca-Blinder, utiliza o propensity score matching para reponderar as probabilidades que serão utilizadas na estimação da regressão quantílica de influência recentrada (RIF regression). Nesse momento, a distribuição dos salários é separada em quantis. Os resultados de ambas as metodologias corroboram a hipótese que norteou esse estudo, de que existe uma massa de trabalhadores auferindo rendimentos maiores do que aqueles alocados no setor industrial. Contudo, foi 
possível observar a partir da decomposição por quantis, que isso ocorreu somente nos cargos mais bem remunerados do setor de serviços.

De acordo com os resultados da decomposição de Oaxaca-Blinder, a magnitude dos efeitos se mostrou desigual entre os anos e, somente em 2014 o efeito estrutura, oriundo da existência de características não observáveis (diferença da média dos parâmetros), passou a contribuir para o aumento do diferencial salarial, sendo responsável por 75,2\% do diferencial total observado. Nesse caso, o diferencial salarial está sendo predominantemente determinado por características não observadas no modelo. Ocorreu também uma substancial diminuição do efeito composição na década analisada de aproximadamente 111 p.p. Ademais, através da RIF regression é possível afirmar que entre 2004 e 2014 o hiato salarial a favor do setor de serviços reduziu de $21,6 \%$ para os $18,2 \%$ no quantil mais alto. $\mathrm{O} 10^{\circ}$ quantil, que é um quantil que o setor da indústria remunera melhor, apresentou elevação do hiato.

Em síntese, os resultados mostraram que, embora o diferencial médio evidenciado pela decomposição Oaxaca-Blinder comprove que, para os anos analisados, o setor de serviços foi o setor que apresentou maior rendimento médio, a segunda metodologia proposta, que desagrega a distribuição de salários em quantis, evidenciou que somente para os dois quantis mais altos (25\% e $10 \%$ dos trabalhadores mais ricos) o setor de serviços remunerou mais. Essa diferença diminui à medida que os quantis aumentam até o ponto que essa diferença se inverte e passa a ter comportamento crescente. Nos três anos analisados, o diferencial para o $50^{\circ}$ quantil foi praticamente nulo e, em 2004, o setor de serviços remunerou apenas $0,40 \%$ a mais do que a indústria. Nos outros dois anos a indústria remunerou nesse quantil 1,3\% e 0,37\% a mais do que o setor de serviços para 2009 e 2014, respectivamente.

Como pode ser observado nas estatísticas descritivas, o setor de serviços apresentou proporção de trabalhadores consideravelmente maior do que o setor industrial. Somado a isso, a heterogeneidade do setor de serviços contribuiu para que exista uma gama maior de profissionais altamente qualificados nesse setor. Diante do exposto, o diferencial de rendimentos entre os setores nos maiores quantis será maior do que o observado nos demais quantis, pois, devido a esses fatores, têm-se mais indivíduos sendo mais bem remunerados no setor de serviços, o que se reflete na diferença salarial dos maiores quantis.

A análise por quantis de renda ratificou a conclusão obtida por Dias (2013) de que, com exceção do setor de serviços, é mais dispendiosa a contratação de pessoas menos qualificadas. Para o setor de serviços, o maior custo se concentra entre pessoas com maior escolaridade e que, possivelmente, se encontram nos dois maiores quantis. Ademais, segundo o autor, a contratação de pessoas qualificadas no setor de serviços de alta tecnologia independe dos salários dos demais setores econômicos. O fato da contratação de pessoas menos qualificadas ser mais dispendiosa pode ser uma justificativa para o declínio, observado por Autor (2010), das ocupações ligadas ao ensino médio. Similarmente, foi observada também uma queda na proporção de homens no mercado de trabalho nos Estados Unidos. No presente estudo, essa queda ocorreu predominantemente no setor de serviços. É importante mencionar 
também o crescimento acima da média das atividades de TI quando comparadas ao setor de serviços como um todo.

O diferencial de rendimentos positivo no setor de serviços em relação ao setor da indústria, mesmo o primeiro tendo maior capacidade de absorver mão de obra menos qualificada, pode ser explicado pelo fato da oferta de mão de obra ser maior do que a demanda de mão de obra no setor industrial dado os avanços tecnológicos desse setor. O estudo feito por Domingues et al. (2016) corrobora a hipótese anterior ao afirmar que a conjuntura econômica favorável para o Brasil no período entre 2005 e 2011 gera questionamentos sobre a escassez de mão de obra especializada, que afetaria principalmente o setor industrial.

Uma das limitações deste estudo é que não foi possível realizar a desagregação das atividades entre os setores por dois motivos. O primeiro deles é relacionado à existência de correlação entre as atividades com as variáveis "faixas de estudo" e "experiência". Por último, a amostra também passou a possuir um número não representativo de observações, o que comprometeria a realização do propensity score matching. Essas razões tornaram a identificação de quais atividades se encontram em cada quantil de rendimento inviável.

Em suma, os resultados indicam que existe uma concentração de renda no setor de serviços, que é observado nos $75^{\circ}$ e $90^{\circ}$ quantis. Isso ocorre devido aos maiores salários estarem concentrados em uma pequena parcela dos trabalhadores desse setor. Diante da representatividade do setor de serviços para o produto interno bruto (PIB) da economia, existe a necessidade de criação de uma política focalizada para os trabalhadores do setor de serviços com cargos que remuneram nos três quantis mais baixos da distribuição de salários, com o objetivo de tornar a distribuição mais homogênea. Diferentemente da indústria, onde os trabalhadores nos quantis mais baixos são mais bem remunerados quando comparado com o setor de serviços.

Diante do apresentado, conclui-se que a decomposição dos rendimentos por quantis se faz necessária devido ao comportamento heterogêneo que as variáveis de controle podem assumir em cada ponto da distribuição de salários. O impacto de cada covariável na redução ou no aumento do diferencial de rendimentos é uma ferramenta que pode auxiliar na formulação de políticas futuras.

\section{Referências bibliográficas}

ACEMOGLU, D.; AUTOR, D. Skill, tasks and technologies: implications for employment and earnings. Cambridge: National Bureau of Economic Research, Jun. 2010. (Working Paper, n. 16082).

AMORIM, B. M. F.; SERVO, L. M. S.; FURTADO, P. RIBEIRO, E. P.; SOUZA, A. L. Criação, destruição e realocação de postos de trabalho por setores. In: CORSEUIL, C. H.; SERVO, L. M. S. (Org.). Criação, destruição e realocação de empregos no Brasil. Brasília: Ipea, 2006. 
ARABSHEIBANI, G. R.; CARNEIRO, F. G.; HENLEY. Gender wage differentials in Brazil: trends over a turbulent era. World Bank, Oct. 2003. (Research Working Paper, n. 3148).

ARAÚJO, V. F.; RIBEIRO, E. P. Diferenciais de salário por gênero no Brasil: uma análise regional. Revista Econômica do Nordeste, Fortaleza, v. 33, n. 2, abr./jun. 2002.

AUTOR, D. The polarization of job opportunities in the U.S. Labor Market: implications for employment and earnings. Washington, DC: The Center for American Progress and The Hamilton Projec0, Apr. 2010.

BACHA, E.; de BOLLE, M. B. Introdução. BACHA, E.; de BOLLE, M. B. (Org). O futuro da indústria no Brasil. Rio de Janeiro: Civilização Brasileira, 2013.

BASTOS, S. Q. A.; SOUZA, K. B. de; PEROBELLI, F. S. O dinamismo do setor de serviços e sua interação com o setor industrial: uma análise para a região Sudeste no período pós Plano Real. In: ENCONTRO ASSOCIAÇÃO NACIONAL DOS CENTROS DE PÓSGRADUAÇÃO EM ECONOMIA. Salvador, dez. 2008. 19p.

BARROS, G. S. C. Agricultura e indústria no desenvolvimento brasileiro. In: BUAINAIN, A.M., ALVES. E., SILVEIRA, J.M.; NAVARRO, Z. (Ed.). O mundo rural no Brasil do século 21: a formação de um novo padrão agrário e agrícola. Brasília, DF: Embrapa, 2014. p. 79-116.

BAUMOL, W. J. Association macroeconomics of unbalanced growth: the anatomy of urban crisis. The American Economic Review, v. 57, n. 3, p. 415-426, Jun. 1967.

BECKER, K. L.; KASSOUF, A. L. Diferença salarial e aposentadoria dos professores do ensino fundamental. Economia Aplicada, v. 16, n. 1, p. 77-104, 2012.

BLINDER, A. Wage discrimination: reduced form and structural estimates. The Journal of Human Resources. v. 4, p. 436-55, 1973.

BONELLI, R.; PESSOA, S.; MATOS, S. Desindustrialização no Brasil: fatos e interpretação. In: BACHA, E.; DE BOLLE, M. B. (Org.). O futuro da indústria no Brasil: desindustrialização em debate. Rio de Janeiro: Civilização Brasileira, 2013.

BROADBERRY, S.; GUPTA, S. The historical roots of India's service-led development: a sectoral analysis of Anglo-Indian productivity differences, 1870-2000. Explorations in Economic History, Elsevier, v. 47, n. 3, p. 264-278, 2010.

COELHO, A. M.; CORSEUIL, C. H. Diferenciais salariais no Brasil: um breve panorama. Rio de Janeiro: Ipea, 2002. (Texto para Discussão, n. 923).

CORSEUIL, C. H.; REIS, M. C.; Critérios de classificação para ocupação: consequências para a caracterização do setor informal e para análises de bem-estar no Brasil. Estudos Econômicos, Belo Horizonte, v. 45, n. 1, p. 5-31, jan./mar. 2015. 
CORSEUIL, C. H.; SERVO, L. M. S.; RIBEIRO, E. P. Introdução. In: CORSEUIL, C. H.; SERVO, L. M. S. (Org.). Criação, destruição e realocação de empregos no Brasil. Brasília: Ipea, 2006.

CRUZ, B. O.; SANTOS, I. R. S. Dinâmica do emprego industrial no Brasil entre 1990 e 2009: uma visão regional da desindustrialização. Rio de Janeiro: Ipea, 2011. (Texto para Discussão, n. 1673).

DIAS, J. Desafios da qualificação no Brasil: demandas dos setores tradicionais e tecnológicos de curto e longo prazo por mão-de-obra qualificada. Rio de Janeiro: BNDES/Anpec, fev. 2013. (Série Working Paper, n. 47).

DOMINGUES, E. P.; SOUZA, K, B. de; CARDOSO, D. F.; CARVALHO, T. S.; SANTIAGO, F. S.; MAGALHÃES, A. S.; BETARELLI JÚNIOR, A. A. A dinâmica do emprego na indústria brasileira: comportamento recente (2006-2010) e o efeito de restrições de mão de obra especializada. Estudos Econômicos, v. 46, n. 3, p. 539-578, set. 2016.

DU CAJU, P.; RYCX, F.; TOJEROW, I. Inter-industry wage differentials: how much does rent sharing matter? The Manchester School, v.79, p. 691-717, 2011.

FARLIE, R. W. An extension of the Blinder-Oaxaca decomposition technique to logit and probit models. Journal of Economic and Social Measurement. v. 30, p. 305-316, 2005.

FIRPO, S.; FORTIN, N. M.; LEMIEUX, T. Decomposing wage distributions using recentered influence function regression. Columbia: Department of Economics, University of British, Jun. 2007. (Working Paper).

FIRPO, S.; FORTIN, N. M.; LEMIEUX, T. Unconditional quantile regressions. Econometrica, v. 77, n. 3, 2009.

FREIRE, C. T. Um estudo dos serviços intensivos em conhecimento no Brasil. In: DE NEGRI, J. A. de; KUBOTA, L. C. (Org.). Estrutura e dinâmica do setor de serviços no Brasil. Brasília: Ipea, 2006.

GOTTSCHALK, M. V.; ALVES, P. Diferenciais de salários no setor de serviços. In: DE NEGRI, J. A.; DE NEGRI, F.; COELHO, D. (Org.). Tecnologia, exportação e emprego. Brasília: Ipea, 2006.

HOEKMAN, B.; MATOO, A. Services trade and growth. World Bank Policy Research Jan. 2008. (Working Paper, n. 3148).

INSTITUTO BRASILEIRO DE GEOGRAFIA E ESTATÍSTICA (IBGE). Pesquisa Nacional por Amostra de Domicílios. Microdados. Disponível em: http://www.ibge.gov.br/home/ estatistica/populacao/trabalhoerendimento/pnad2015/microdados.shtm. Acesso em: 20 out. 2015.

INSTITUTO BRASILEIRO DE GEOGRAFIA E ESTATÍSTICA (IBGE). Pesquisa Nacional por Amostra de Domicílios 2014 (PNAD-2014). Disponível em: ftp://ftp.ibge.gov.br/Trabalho 
_e_Rendimento/Pesquisa_Nacional_por_Amostra_de_Domicilios_anual $/$ microdados $/ 2014 / /$. Acesso em: 20 out. 2015.

INSTITUTO BRASILEIRO DE GEOGRAFIA E ESTATÍSTICA (IBGE). Pesquisa Nacional por Amostra de Domicílios. Metodologia. Anexo III - Composição dos grupamentos de atividades. Disponível em: <http://www.ibge.gov.br/home/estatistica/populacao/ trabalhoerendimento/pnad2015/microdados.shtm>. Acesso em: 10 jan. 2017.

INSTITUTO BRASILEIRO DE GEOGRAFIA E ESTATÍSTICA (IBGE). Serviços. Brasil em Síntese. Disponível em: http://brasilemsintese.ibge.gov.br/servicos.html. Acesso em: 4 jan. 2016.

INSTITUTO DE PESQUISA ECONÔMICA APLICADA (IPEA). Mercado de trabalho. Carta de Conjuntura, Brasília, Ipea, n. 23, jun. 2014. Acesso em: 14 jul. 2015.

INSTITUTO BRASILEIRO DE GEOGRAFIA E ESTATÍSTICA (IBGE). Mercado de trabalho. Carta de Conjuntura, Brasília, Ipea, n. 27, jum. 2015. Acesso em: 14 jul. 2015.

JACINTO, P. A. R.; PONTUAL, E. Crescimento da produtividade no setor de serviços e da indústria no Brasil: dinâmica e heterogeneidade. Economia Aplicada, v. 19, n. 3, p. 401-427, jul./set. 2015.

JESUS, J. G. A evolução do diferencial de rendimentos entre negros e brancos nos setores agrícola e não agrícola no Brasil. Revista Orbis Latina, v. 4, n. 1, p. 159-185, 2015.

KALDOR, N. A model of economic growth. Economic Journal, Cambridge, v. 67, p. 591-624, 1957.

KENESSEY, Z. The primary, secondary, tertiary and quaternary Sectors of the Economy. The Review of Income and Wealth, v. 33, n. 4, p. 359-385, Dec. 1987.

KON, A. Sobre as atividades de serviços: revendo conceitos e tipologias. Revista de Economia Política, v. 19, n. 2, 1999.

KON, A. Economia de serviços. Rio de Janeiro: Campus/Elsevier, 2004.

KUBOTA, L. C. Apresentação. In: DE NEGRI, J. A. de; KUBOTA, L. C. (Org.). Estrutura e dinâmica do setor de serviços no Brasil. Brasília: Ipea, 2006.

KUBOTA, L. C. A inovação tecnológica das firmas de serviços no Brasil. In: DE NEGRI, J. A. de; KUBOTA, L. C. (Org.). Estrutura e dinâmica do setor de serviços no Brasil. Brasília: Ipea, 2006.

LOVELL, P. A. Race, gender, and work in São Paulo, Brazil, 1960-2000. Latin American Research Review, v. 41, n. 3, p. 63-87, 2006.

MEIRELES, D. C. Diferenciais de rendimentos por gênero: uma análise dos efeitos composição e estrutura salarial no Brasil (1976, 1987, 1996 e 2009). 2014. 93f. Dissertação 
(Mestrado em Economia Regional)-Universidade Federal do Rio Grande do Norte, Natal, 2014.

MELO, H. P. de; ROCHA, F.; FERRAZ, G.; DI SABBATO, A.; DWECK, R. O setor de serviços no Brasil: uma visão global - 1985/95. Rio de Janeiro: Ipea, 1998. (Texto para Discussão, n. 579).

MINCER, J. Schooling, experience and earning. New York: NBER, 1974.

O'NEILL, J. The gender gap in wages, circa 2000. The American Economic Review, v. 93, n. 2, p. 309-314, Jan. 2003.

OAXACA, R., Male-female wage differentials in urban labor market, International Economic Review, Osaka, v. 14, n. 23, p. 693-709, 1973.

OMETTO, A. M. H.; HOFFMANN, R.; ALVES, M. C. A segregação por gênero no mercado de trabalho nos estados de São Paulo e Pernambuco. Economia Aplicada, v. 1, n. 3, p. 393423, 1997.

OMETTO, A. M. H.; HOFFMANN, R.; ALVES, M. C. Participação da mulher no mercado de trabalho discriminação em Pernambuco e em São Paulo. Revista Brasileira de Economia, Rio de Janeiro. v.53, n.3, p.287-322. jul./set. 1999.

ORGANISATION FOR ECONOMIC CO-PERATION AND DEVELOPMENT (OECD). Innovation and knowledge-intensive Services Activities. Paris: OECD Publishing, 2006. Disponível em: http://www.keepeek.com/Digital-Asset-Management/oecd/science-andtechnology/innovation-and-knowledge-intensive-service-activities_9789264022744-en.

Acesso em: 31 out. 2016.

PARNES, B.; HARTUNG, G. Uma nota sobre a desaceleração recente da indústria brasileira. In: BACHA, E.; DE BOLLE, M. B. (Org.). O futuro da indústria no Brasil: desindustrialização em debate. 1 ed. Rio de Janeiro: Civilização Brasileira, 2013.

PASTORE, A. C.; GAZZANO, M.; PINOTTI, M. C. Por que a produção industrial não cresce desde 2010?. In: BACHA, E.; DE BOLLE, M. (Org.). O futuro da indústria no Brasil: desindustrialização em debate. Rio de Janeiro: Civilização Brasileira, 2013.

PEREIRA, M. Z.; BASTOS, S.; PEROBELLI, F. S. Análise Sistêmica do setor de serviços no Brasil (2005). In: ENCONTRO ASSOCIAÇÃO NACIONAL DOS CENTROS DE PÓSGRADUAÇÃO ECONOMIA, Porto de Galinhas, dez. 2012, 20p.

PINHEIRO, A. C.; RAMOS, L. Interindustry wage differentials and earning inequality. Estudios de Economia, v. 21, n. 1, p. 79-111, 1994.

REIS, M. C. Fields of study and earnings gap by race in Brazil. Review of Development Economics, v. 21, n. 3, p. 756-785, Aug. 2017. 
ROCHA, S. A investigação da renda nas pesquisas domiciliares. Economia e Sociedade, Campinas, v. 12, n. 2 (21), p. 205-224, jul./dez. 2003.

ROWTHORN, R.; RAMASWANY, R. Growth, trade and desindustrialization. IMF Staff Papers, v. 46, n. 1, 1999.

ROWTHORN, R.; WELLS, J. R. De-industrialization and foreign trade. Cambridge: Cambridge University Press, 1987.

SACHSIDA, A.; LOUREIRO, P. R.; MENDONÇA, M. J. C. de. Um estudo sobre escolaridade. Revista Brasileira de Economia, v. 58, n. 2, p. 249-265, ago. 2007.

SCATOLIN, F. D.; CRUZ, M. J. V.; PORCILE, G.; NAKABASHI, L. Desindustrialização? Uma análise comparativa entre Brasil e Paraná. Indicadores Econômicos FEE, v. 35, n. 1, p. 105-120, ago. 2007.

SILVA, A. M.; DE NEGRI, J. A.; KUBOTA, L. C. Estrutura e dinâmica do setor de serviços no Brasil. In: DE NEGRI, J. A. de; KUBOTA, L. C. (Org.). Estrutura e dinâmica do setor de serviços no Brasil. Brasília: Ipea, 2006.

SILVA, R. A. Evolução recente do terciário (serviços) no Brasil. 2009. Tese (Doutorado em Desenvolvimento Econômico)-Instituto de Economia, Universidade Estadual de Campinas, Campinas, 2009.

SQUEFF, G. C. Desindustrialização no Brasil: luz e sombras no debate brasileiro. Brasília: Ipea, 2012. (Texto para Discussão, n. 1747).

TREGENNA, F. Characterizing deindustrialization: an analysis of changes in manufacturing employment and output internationally. Cambridge Journal of Economics, v. 33, n. 3, p. 433466, May 2008.

VAZ. D. V.; HOFFMANN, R. Remuneração nos serviços no Brasil: o contraste de funcionários públicos e privados. Economia e Sociedade, Campinas, v. 16, n. 2, p. 199-232, ago. 2007.

VALOTTO, G. P. La evolución en la consideración económica del sector servicios. Revista Contribuciones a la Economía, 2011. Disponível em: http://www.eumed.net/ce/2011a/. Acesso em: 10 out. 2015.

VILELA, T.; ARAÚJO, E.; RIBEIRO, E. Análise do diferencial de renda do trabalho em 2008 entre diferentes gerações de trabalhadores no Brasil. Revista EconomiA, maio/ago. 2012. 


\section{Apêndice}

Denominações das atividades a partir da CNAE-IBGE

\begin{tabular}{|c|c|}
\hline Código & Denominações \\
\hline 210 & Fabricação de celulose, papel e produtos de papel \\
\hline 220 & Fabricação de papelão corrugado e de embalagens e artefatos de papel e papelão \\
\hline 230 & $\begin{array}{l}\text { Fabricação de coque, refino de petróleo, elaboração de combustíveis nucleares e produção de } \\
\text { álcool }\end{array}$ \\
\hline 240 & Fabricação de produtos químicos \\
\hline 250 & Fabricação de artigos de borracha e plástico \\
\hline 290 & Fabricação de máquinas e equipamentos \\
\hline 300 & Fabricação de máquinas para escritório e equipamentos de informática \\
\hline 310 & Fabricação de máquinas, aparelhos e materiais elétricos \\
\hline 320 & Fabricação de material eletrônico e de aparelhos e equipamentos de comunicações \\
\hline 330 & $\begin{array}{l}\text { Fabricação de equipamentos de instrumentação médico-hospitalares, instrumentos de precisão e } \\
\text { ópticos, equipamentos para automação industrial, cronômetros e relógios }\end{array}$ \\
\hline 340 & Fabricação e montagem de veículos automotores, reboques e carrocerias \\
\hline 350 & Fabricação de outros equipamentos de transporte \\
\hline 640 & Correios e telecomunicações \\
\hline 650 & Intermediação financeira, exclusive seguros e previdência privada \\
\hline 660 & Seguros e previdência privada \\
\hline 670 & Atividades auxiliares da intermediação financeira \\
\hline 700 & Atividades imobiliárias \\
\hline 720 & Atividades de informática e conexas \\
\hline 730 & Pesquisa e desenvolvimento das ciências sociais e humanas \\
\hline 740 & Serviços prestados principalmente às empresas \\
\hline 800 & Educação \\
\hline 920 & Atividades recreativas, culturais e desportivas \\
\hline
\end{tabular}

Fonte: Baseado na PNAD-IBGE (Anexo III). 